\title{
7.3 AbBildungen
}

Abbildung 1: Repositorium: Menüleiste (Stand: März 2018). 96

Abbildung 2: Repositorium: Erweiterte Suchfunktion (Stand: März 2018). 97

Abbildung 3: Originalansicht des Repositoriums (Stand: März 2018). 99

Abbildung 4: Repositorium: Analyseansicht (Stand: März 2018). 100

Abbildung 5: Repositorium: Beispiel einer Suchanfrage (Stand: März 2018). 103

\subsection{TABELLEN}

Tabelle 1: $\quad$ Französischsprachige Moralische Wochenschriften im Repositorium (Stand: März 2018). 92

Tabelle 2: $\quad$ Spanischsprachige Moralische Wochenschriften im Repositorium (Stand: März 2018). 93

Tabelle 3: Themenauszeichnung innerhalb des digitalen Repositoriums (Stand: März 2018). $\quad 98$

Tabelle 4: $\quad$ Spectatoriale Tugend- und Lasterattribute. 283

Tabelle 5: $\quad$ Stereotype (Rollen-)Bilder in den Moralischen Wochenschriften.

Tabelle 6: Frauen- und Männerbild-Markups in den französischsprachigen Wochenschriften. 345

Tabelle 7: $\quad$ Frauen- und Männerbild-Markups in den spanischsprachigen Wochenschriften. $\quad 346$

Tabelle 8: Absolute Häufigkeiten der Textsorten in den Nummern mit Frauen- und Männerbild-Markup in den französischsprachigen Wochenschriften.

Tabelle 9: Absolute Häufigkeiten der Textsorten in den Nummern mit Frauen- und Männerbild-Markup in den spanischsprachigen Wochenschriften.

\subsection{Diagramme}

Diagramm 1: Frauen- und Männerbild-Markups in den französischsprachigen Moralischen Wochenschriften (chronologische Reihung).

Diagramm 2: Frauen- und Männerbild-Markups in den spanischsprachigen Moralischen Wochenschriften (chronologische Reihung).

Diagramm 3: Textsorten in den 183 französischsprachigen Frauen- und Männerbild-Nummern.

Diagramm 4: Textsorten in den 71 spanischsprachigen Frauen- und Männerbild-Nummern. 